\title{
ДОКАЗАТЕЛЬНАЯ МЕДИЦИНА В ГИНЕКОЛОГИИ: ИСПОЛЬЗОВАНИЕ В РОССИИ И МИРЕ
}

\section{Островерх Алина Александровна}

студент

Полицеальная школа Cosinus в Варшаве

Аннотация: Доказательная медицина основывается на научных клинических исследованиях, анализе данных с последующим применением методов лечения, препаратов, методики, доказавших свою эффективность. В мире используется самым активным образом, все медицинские рекомендации, протоколы лечения основываются на научно доказанных фактах. Однако внедрение в России только ведется, и осуществляется данный процесс весьма медленно, потому и имеет место проблема разного подхода к лечению заболеваний, проблема использования препаратов с низкой эффективностью, проблема применения низкоэффективных методик. В статье представлена попытка анализа применения доказательной медицины в гинекологии в Российской Федерации в сравнении с зарубежными странами.

Ключевые слова: доказательная медицина, доказательная гинекология, гинекология, клинические исследования

\section{EVIDENCE-BASED MEDICINE IN GYNECOLOGY: USAGE IN RUSSIA AND THE WORLD}

\section{Ostroverkh Alina} student

Policeal school in Warsaw

\begin{abstract}
Evidence-based medicine is based on scientific clinical studies, data analysis, followed by the use of treatment methods, drugs, techniques that have proven their effectiveness. It is used in the most active way in the world, all medical recommendations, treatment protocols are based on scientifically proven facts. However, the introduction in Russia is only underway, and this process is very slow, therefore there is a problem of a different approach to the treatment of diseases, the problem of using drugs with low efficiency, the problem of using lowefficiency techniques. The article presents an attempt to analyze the use of
\end{abstract}


evidence-based medicine in gynecology in the Russian Federation in comparison with foreign countries.

Key words: evidence-based medicine, evidence-based gynecology, gynecology, clinical research

Понятие «медицина, основанная на доказательствах», было предложено канадскими учеными из университета Мак-Мастера г. Торонто в 1990 г. В настоящее время доказательная медицина рассматривается в качестве добросовестного, точного и осмысленного использования лучших результатов клинических исследований для выбора лечения конкретного больного [6].

Американо-канадский врач, пионер в области доказательной медицины Дэвид Лоуренс Сакет определил доказательную медицину как систематическое использование лучших из существующих доказательств эффективности при выборе метода лечения [14]. Таким образом, доказательная медицина не является новой наукой, это, скорее, качественно новый подход, направление или технология сбора, анализа и интерпретации научной информации.

Появление доказательной медицины объясняется наметившейся в конце прошлого столетия тенденцией к стабильному росту объема научной информации, в частности в области клинической фармакологии, с развитием которой в медицинскую практику стали внедряться все новые и новые лекарственные средства, и появилась необходимость в качественном анализе их эффективности, выявлении влияния на организм человека. Соответственно, появилась острая необходимость в комплексном анализе, обобщении и структурировании имеющейся информации.

Другая причина развития доказательной медицины - нехватка средств, связанная с ростом расходов на здравоохранение. Сегодня создалась такая ситуация, что, по мнению экспертов Всемирной организации здравоохранения (BO3), ни в одной стране мира недостаточны расходы на здравоохранение [2]. В этой ситуации из большого числа лекарственных средств (в настоящее время в российском государственном реестре лекарственных средств находятся около 16 тысяч препаратов, всего же зарегистрировано порядка 70 тысяч [4]) необходимо выбрать именно те, которые обладают наиболее высокой эффективностью и лучше переносятся больными.

Важнейшими характеристиками, наиболее точно отражающими сущность доказательной медицины, являются следующие ее основные принципы: 
1) прозрачность. Любое клиническое решение (выбор варианта лечения из возможных альтернатив) должно быть обосновано доказательствами, которые могут быть проверены другими людьми;

2) равноправие. Авторитет, статус и личный опыт не должны влиять на выбор лечения, такой выбор должен основываться на качественных доказательствах преимуществ конкретного метода [8, с. 96-97].

В настоящее время выделяют несколько уровней доказательности:

Уровень А - доказательства получены на основе мета-анализа (сравнительного) одного или нескольких рандомизированных контролируемых исследований. Это самый высокий уровень доказательности.

Уровень В - доказательства получены на основе данных контролируемого нерандомизированного исследования.

Уровень С - доказательства получены на основе данных описательных, сравнительных, одномоментных исследований.

Уровень Д - доказательства получены на основе исследований отдельных случаев, консенсусов специалистов и заключений экспертных комитетов.

Самый низкий уровень доказательности - личный опыт врача [13].

Очевидным преимуществом медицины, основанной на доказательствах, является использование лишь тех лекарственных средств, методик лечения, которые показали свою эффективность, что дает возможность осуществлять лечение с максимальной пользой для пациента и минимальными возможными негативными последствиями, экономически целесообразное.

Доказательная медицина работает в интересах людей, максимально лишена конфликта интересов, настолько, насколько это возможно в современном мире. Она не шаблонная, не отменяет индивидуальный подход, а только способствует ему, и не требует бездумного следования протоколу, поскольку необходимо также наличие у врача клинического и логического мышления, имения постановки правильного диагноза, и выбора подходящего протокола, метода диагностики или лечения [1, с. 13].

Одной из сфер медицины, где доказательный подход используется активно, является гинекология. К сожалению, современная реальность Российской Федерации такова, что многие врачи-гинекологи, не желая разбираться в сущности доказательной медицины, не имея стремлений к саморазвитию и обновлению знаний, работают «по старинке», в своей практике используя устаревшие методы, неэффективные лекарственные средства. 
В этой связи показателен опыт зарубежных стран, где следование принципам доказательной медицины - неотъемлемый атрибут работы врачейгинекологов.

Например, гестагены (прогестерон, медроксипрогестерон, дидрогестерон и т.д.) в широком разнообразии представленные на отечественном рынке под разными торговыми марками, обоснованы к назначению в I триместре беременности в следующих случаях (имеют уровень доказательности A -la):

- прерывание беременности вследствие недостаточности лютеиновой фазы менструального цикла

- прерывание беременности, обусловленное наличием хронического эндометрита;

- угроза прерывания беременности при наличии ретрохориальной гематомы;

- наличие антител к прогестерону;

- невынашивание вследствие несовместимости супругов по антигенам гистосовместимости [10, с. 378-379].

Однако в России практически каждая женщина, которая обратилась к гинекологу при минимальных жалобах на кровянистые выделения, ноющие боли внизу живота или мифический тонус во время беременности (данное понятие отсутствует в международных клинических рекомендациях и протоколах), на нерегулярный цикл получает рекомендацию принимать один из препаратов прогестерона [12]. Статистика такова, что препараты прогестерона относятся к числу наиболее часто назначаемых в России (27 место в списке назначаемых препаратов в 2017 г. [9]), тогда как в западных странах они не входят даже в топ-50 (например, в США - 65 место [7]).

Таким образом, налицо проблема повсеместного назначения гестагенов, которые у многих врачей выступают лекарством от всех гинекологических болезней, а также средством для повышения фертильности. Назначение прогестеронов при планировании беременности во 2 фазе цикла практически повсеместная практика, которая приводит к тому, что дефицит прогестерона действительно будет восстановлен в организме женщины, но это не приведет к восстановлению овуляции, а, следовательно, не поможет забеременеть [белоконь, с. 30].

Сделаем вывод, что доказательное применение препаратов прогестерона ограничено небольшим числом показаний, тогда как в России они назначаются практически повсеместно. 
В 70-х годах в США широко использовался синтетический прогестерон женщинами в первом триместре беременности. И вдруг появились данные, что синтетический прогестерон может вызвать появление небольших (малых) пороков развития у плода, особенно половых органов девочек и мальчиков. Федеральная лекарственная администрация США (FDA) запретила использование прогестерона у беременных женщин в первом триместре, а в инструкции по применению препарата появилось утверждение «прием прогестерона противопоказан при беременности сроком до 4 месяцев, так как он может вызвать малые пороки развития плода», и дальше шло детальное описание всех видов пороков, которые были зарегистрированы в тех случаях, где женщины использовали прогестерон в первом триместре. Кроме того, доказана связь между прогестероновыми препаратами и повышением риска внематочной беременности [3].

Таким образом, в западных странах, врачи-гинекологи в которых повсеместно работают исключительно по рекомендациям и протоколам, основанным на препаратах с доказанной клинической эффективностью, используется иной подход и к назначению препаратов прогестерона, в России же они назначаются подавляющему числу женщин, вне зависимости от наличия у них прямых показаний, в отношении которых препараты имеют доказанную эффективность.

Еще одним примером разных подходов в гинекологии является регламент действий врачей-гинекологов при угрозе самопроизвольного выкидыша (прерывание беременности на сроке до 22 недель).

За рубежом таких женщин просто отправляют домой: им «прописывают» постельный режим, общее клиническое обследование, половой покой. Время покажет, чем закончится эта ситуация: или беременность сохранится, или произойдет выкидыш, если она заложилась некачественной, - и это хорошо, что она была «отбракована» организмом. В Российской Федерации, напротив, угрожающий выкидыш является непременным показанием для госпитализации в стационар: пациентке назначают «но-шпу», препараты-токолитики, которые расслабляют матку, кровоостанавливающие препараты, препараты прогестерона. Это не вопрос биологических или медицинских различий - это вопрос психологии большей части нашего населения: если врач не дал таблетку, значит он не стремился помочь. И довольно трудно донести до людей, что тут действуют законы природы - на них не повлияешь. Согласно отечественным протоколам, 
протоколу врач не имеет права не предложить госпитализацию при угрозе выкидыша.

Однако научные медицинские факты ясно показывают, что госпитализация ничего принципиально не меняет в прогнозе: вероятность самопроизвольного выкидыша от этого никак не снижается. Клинические исследования доказали, что нет медикаментов, которые справляются со спонтанным выкидышем. Если беременность сохраняется, то это природа сохраняет беременность, а не лечение. Для привычного выкидыша такие медикаменты есть: если удалось выявить причину повторных прерываний беременности, на нее можно воздействовать. Это лечение назначают еще либо до наступления беременности, либо на ранних этапах беременности, до появления каких-либо симптомов угрозы прерывания [3].

Таким образом, можно заключить, что если беременность сохранилась на фоне препаратов прогестерона, она сохранилась бы и без него, и наоборот (если беременность прервалась без препаратов прогестерона, она прервалась бы и с этими препаратами), что доказано клиническим исследованиями [5]. В этом и отличается подход в гинекологии, основанный на доказательной медицине, используемый в западных странах, и не основанный на таковой, имеющий место в России.

Еще одним примером разного подхода в России и западных странах, придерживающихся принципов доказательной медицины, является тот факт, что в рекомендациях Королевского колледжа акушеров и гинекологов (Лондон, Великобритания) [15] четко указано, что разумно не использовать токолитические препараты, поскольку нет четких доказательств того, что они улучшают исход. Тем не менее, следует рассмотреть вопрос о токолизе, если несколько выигранных дней можно будет использовать с пользой, например, для завершения курса кортикостероидов или внутриутробного переноса (уровень рекомендаций А). Также недостаточно данных для того, чтобы сделать какие-либо твердые выводы о целесообразности поддерживающей токолитической терапии после угрозы преждевременных родов. Следовательно, поддерживающая терапия не может быть рекомендована для повседневной практики (уровень доказательности Іа). Однако многие врачи, особенно в развивающихся странах, в т.ч. и в России, по-прежнему продолжают использовать пероральные токолитики, такие как изоксуприн или сальбутамол, неделя за неделей на протяжении всей беременности.

Перечисленные выше факторы являются лишь несколькими яркими примерами, показывающими, что отечественная клиническая практика 
по-прежнему нуждается в значительном улучшении и практике, основанной на фактах.

Подводя итог проведенного анализа, еще раз отметим, что доказательная медицина - это новая парадигма клинической медицины, отличающаяся меньшим воздействием субъективного фактора на выбор критериев диагностики и терапии и требующая от врача критической оценки мнений разных экспертов и результатов клинических исследований. Информация, полученная в исследованиях, проведенных в соответствии с принципами доказательной медицины, является наиболее достоверной [11, c. 127].

Доказательная медицина изменила способы оказания медицинской помощи во всем мире. Он сочетает в себе индивидуальный клинический опыт с наилучшими имеющимися данными исследований, чтобы пациенты получали лечение на высоком уровне Акушеры и гинекологи должны иметь возможность доступа и критической оценки последних данных в своей области знаний и применения их в клинической практике для обеспечения наилучших результатов для женщин, находящихся под их опекой.

Применение принципов доказательной медицины в гинекологии способствует тому, что женщины получают лечение лишь препаратами, которые доказали свою эффективность, методы лечения также избираются исключительно те, что показали достоверную значимость, что и является важнейшим отражением принципа «Primum non nocere», т.е. «Не навреди».

\section{Список литературы}

1. Белоконь, О.А. Я - женщина. Все о женском здоровье, контрацепции, гормонах и многом другом / О.А. Белоконь. - М.: АСТ, 2020. 448 c.

2. ВО3: достигнута важная глобальная веха в деле обеспечения всеобщего охвата услугами здравоохранения [Электронный ресурс]. - Режим доступа: https://www.who.int/ru/news/item/17-10-2019-universal-health-coveragepasses-key-global-milestone

3. Глобальный миф о прогестероне [Электронный ресурс]. - Режим доступа: https://doctorberezovska.com/globalnyj-mif-o-progesterone-chitat-vsemzhenshhinam/

4. Государственный реестр лекарственных средств [Электронный ресурс]. - Режим доступа: https://grls.rosminzdrav.ru/grls.aspx 
5. Дюфастон и Утрожестан: всем и каждому или никогда и никому? [Электронный ресурс]. - Режим доступа: http://rumyantsevamd.ru/ duphaston_utrogestan/

6. Понятие «Evidence-based Medicine» («медицина, основанная на доказательствах») [Электронный ресурс]. - Режим доступа: https://www. healthquality.ru/open/index_con.php?ac=index\&mod_id=21\&obj=co_staticpages

7. Рейтинг лекарственных средств в США [Электронный ресурс]. Режим доступа: https://www.apteka.ua/article/12819

8. Талантов, П.В. Доказательная медицина от магии до поисков бессмертия / П.В. Талантов. - М.: АCT: CORPUS, 2019. - 560 с.

9. Фармацевтический рынок России 2017 [Электронный ресурс]. Режим доступа: https://dsm.ru/upload/iblock/ccd/ccd204d12dd79bfdf63b 9c1711671898.pdf

10. Формуляр лекарственных средств в акушерстве и гинекологии / под ред. проф. В.Е. Радзинского. - М.: ГЭОТАР-Медиа, 2013. - 688 с.

11. Хрянин, А.А. Использование макролидов в акушерстве в соответствии с принципами доказательной медицины (рациональной фармакотерапии) / А.А. Хрянин, О.В. Решетников // Медицинский альманах. 2010. - № 4 (13). - C. 127-130.

12. Шутова, Е. «Сначала наденьте маску на себя, а потом на ребёнка»: гинеколог о женском здоровье [Электронный ресурс] / Е. Шутова. - Режим доступа: https://22century.ru/popular-science-publications/gynaecologist

13. Oxford Centre for Evidence-Based Medicine: Levels of Evidence (March 2009) [Электронный ресурс]. - Режим доступа: https://www.cebm.ox.ac.uk/ resources/levels-of-evidence/oxford-centre-for-evidence-based-medicine-levels-ofevidence-march-2009

14. Sackett D.L. Evidence based medicine: what it is and what it isn't [Электронный ресурс] / D.L. Sackett, W.M. Rosenberg, J.A. Gray, R.B. Haynes, W.S. Richardson. - Режим доступа: https://www.ncbi.nlm.nih.gov/pmc/ articles/PMC2349778/

15. Tocolytic drugs for women in preterm labour. RCOG Clinical Green Top Guideline [Электронный pecypc]. - Режим доступа: http://www.sghog.com/guidelines/rcog-green-top-guidelines/

(C) А.А. Островерх, 2021 